\title{
Caracterização de um quintal agroflorestal na Amazônia Central, Brasil
}

\section{João Batista Dias Damaceno* e Ana Cecília Nina Lobato}

Programa de Pós-Graduação em Agronomia Tropical. Universidade Federal do Amazonas. Av. Rodrigo Octavio Jordão Ramos, 6200. Campus da UFAM. Setor Sul. Prédio Pós Bio Agro, 2o andar, Sala de Agronomia. Manaus-AM, Brasil (CEP 69077-000).*E-mail: joaodiasrm@gmail.com.

Resumo. Os quintais agroflorestais na Amazônia constituem-se como meio de subsistência e geração de renda aos agricultores. Assim, o presente trabalho objetivou caracterizar um quintal agroflorestal na Amazônia Central através de levantamentos socioeconômicos, patrimoniais e florísticos. 0 quintal agroflorestal foi dividido em cinco zonas quanto ao aproveitamento da área (Zona 0, 1, 2, 3, 4 e 5). Os proprietários possuíam baixa escolaridade, sem título final da terra e a maior parte da renda advém de aposentadoria. Dentre as espécies vegetais cultivadas no quintal estão o cupuaçu (Theobroma grandiflorum), o açaí (Euterpe oleracea), a mandioca (Manihot esculenta), o mari (Poraqueiba sericea) e a pimenta-do-reino (Piper nigrum). Os cultivos são manejados com baixa tecnologia, sem insumos externos, que favorece a conservação do meio ambiente.

Palavras-chave: Sistema agroflorestal; Agricultura familiar; Segurança alimentar; Amazônia brasileira.

Abstract. Characterization of an agroflorestal yard in the Central Amazon, Brazil. The agroforestry yards in the Amazon are a means of subsistence and income generation for farmers. Thus, the present work aimed to characterize an agroforestry backyard in Central Amazonia through socioeconomic, patrimonial and floristic surveys. The agroforestry yard was divided into five zones regarding the use of the area (Zone $0,1,2$, 3,4 and 5). The owners had low schooling, no final land title and most of the income comes from retirement. Among the cultivated plant species in the garden are cupuaçu (Theobroma grandiflorum), açaí palm (Euterpe oleracea), cassava (Manihot esculenta), mari (Poraqueiba sericea) and black pepper (Piper nigrum). The crops are managed with low technology, without external inputs, that favors the conservation of the environment.

Keywords: Agroforestry system; Family farming; Food safety; Brazilian Amazon.
Recebido:

05/02/2019

Aceito:

$11 / 04 / 2019$

Publicado:

$30 / 04 / 2019$

Acesso aberto

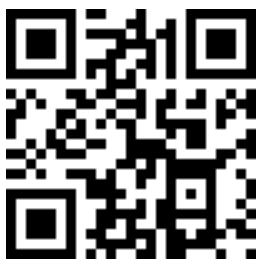

ORCID

(D) 0000-0001-8736-5202

João Batista Dias

Damaceno

D $0000-0002-5357-3748$

Ana Cecília Nina

Lobato 


\section{Introdução}

Sistemas agroflorestais são representados pelo múltiplo uso da terra, podendo incorporar espécies florestais, cultivos agrícolas e espécies animais. Dentre os sistemas conhecidos, destacam-se o silvipastoril, onde árvores são associadas a criação de animais; silviagrícolas, onde árvores são associadas com cultivos agrícolas; agropastoril, onde cultivos agrícolas são associadas a criação de animais e agrossilvipastoril, onde há o consorcio de árvores, cultivos agrícolas e criação de animais (Castro et al., 2009).

Dentre estes, os quintais florestais caracteriza-se pelo agrupamento de várias características desses sistemas, por otimizar os usos dos recurso, além da localização próxima a ao ambiente familiar (Gomes, 2010). Como conceito, um quintal agroflorestal (QAF) é um tradicional sistema familiar de regiões tropicais praticado em zonas rurais e periurbanas e instalado em áreas adjacentes a residências. A composição dos QAF's baseia-se por ampla biodiversidade de espécies agrícolas, florestais e criação de animais, domésticos ou para subsistência (Sablayrolles e Andrade, 2009).

De acordo com Figueiredo Junior et al. (2013), os QAF's são representados por exigirem baixo manejo, com pequeno uso de insumos ou mao-de-obra externa e constituem fonte adicional de renda a família, além de suprir necessidades básicas do dia-a-dia, como alimentos e lenha. Muitos são os benefícios sociais, ambientais e econômicos dos QAF's, tais como a conservação de recursos homeopáticos, a recreação familiar, a conservação da biodiversidade genética in situ, a manutenção do solo e da ciclagem de nutrientes, bem como a geração de renda extra (Sablayrolles e Andrade, 2009).

Vários são os trabalhos realizados na Região Amazônica, em destaque no Estado do Amazonas, em áreas ribeirinhas e de terra firme, que trazem relatos de diversos benefícios, tais como o fortalecimento das relações familiares, o aumento de renda, o aumento da qualidade e quantidade de alimentos durante o ano, bem como o aumento e a manutenção da fertilidade dos solos (Aguiar et al., 2009; Costa e Mitja, 2010; Almeida e Gama, 2014). Segundo Gazel Filho (2008), os estudos relacionados com a composição florística e estrutura dos quintais florestais são importantes para fornecer informações necessárias para a aplicação de técnicas que objetivam intensificar e melhorar as características produtivas dos quintais.

Desta forma, o presente trabalho objetivou a caracterização socioeconômica e o levantamento de espécies florestais, cultivos agrícolas e animais que fazem parte da biodiversidade de um quintal agroflorestal na zona rural de Manaus, Amazonas, Brasil.

\section{Material e métodos}

O trabalho foi desenvolvido no Sítio Água Viva, localizado nas coordenadas geográficas de referência $2^{\circ} 44^{\prime}$ $22.47^{\prime \prime}$ S e $60^{\circ} 9^{\prime} 35.53$ " O, situado no km 21, do Ramal do Pau Rosa, com acesso pela BR-174, no Assentamento Tarumã Mirim, na Zona Rural do Município de Manaus, Amazonas, Brasil (Figura 1). A área é de $150 \mathrm{~m}$ de frente por $1.070 \mathrm{~m}$ de fundo, totalizando 16,05 ha.

De acordo com a classificação de Köppen (1948), o clima em Manaus é classificado como Am (Tropical úmido e subúmido), com temperatura média de $27,4^{\circ} \mathrm{C}$. Na área há predomínio de latossolos e argissolos amarelos com baixa a média fertilidade (Rodrigues, 1996).

O quintal agroflorestal é ocupado desde 2000 por uma família de quatro integrantes, sendo três adultos e uma criança, e, devido ao baixo preço na ocasião, a propriedade foi comprada para estabelecimento, criação de animais e cultivos. Até a realização desta pesquisa, o sítio estava para ser regularizado pelo Instituto Nacional de Reforma Agrária (INCRA). 


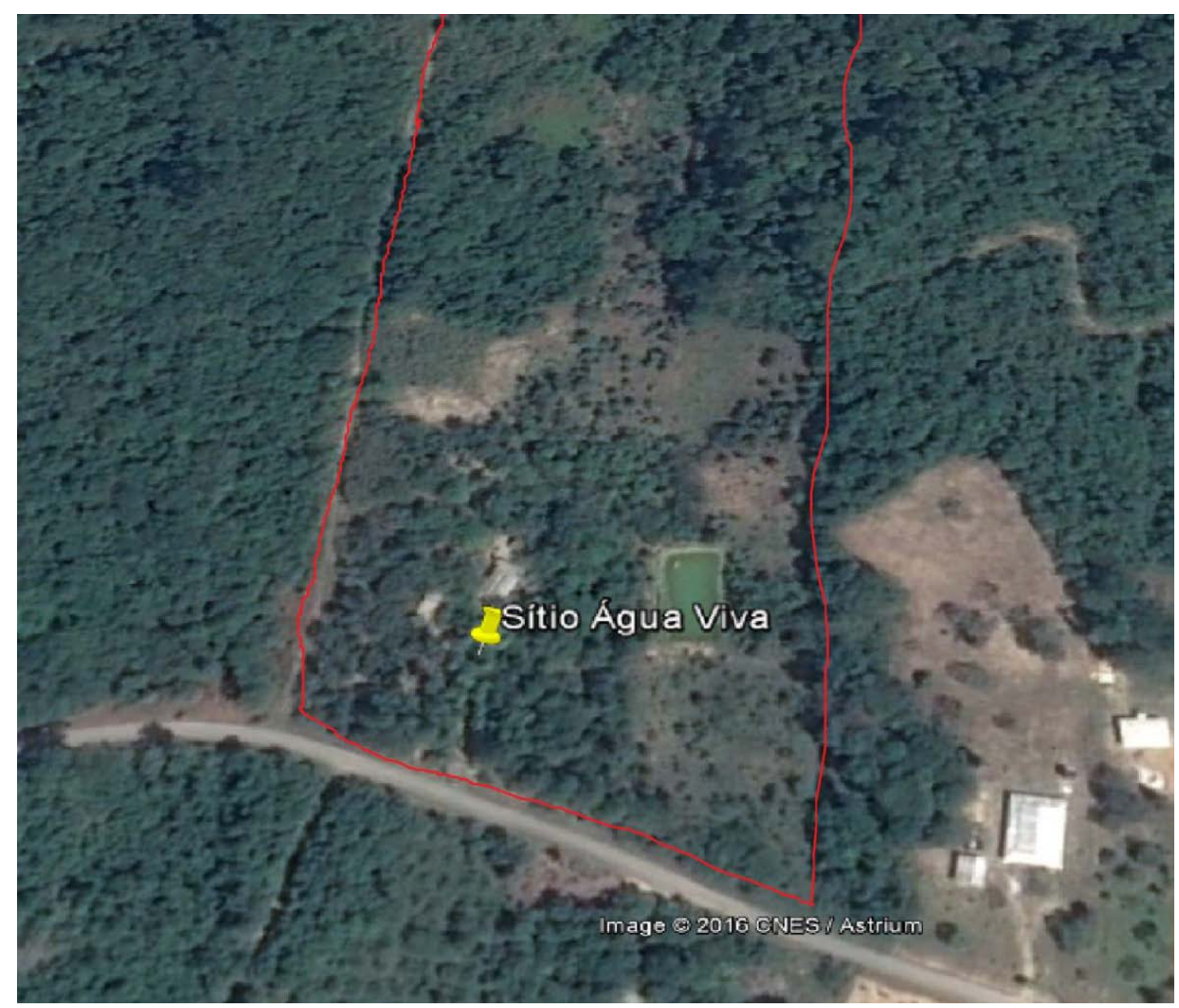

Figura 1. Visão aérea do quintal agroflorestal "Água Viva”.

A técnica de coleta de dados baseou-se em entrevista semiestruturada, com a combinação de perguntas fechadas e abertas, em que o entrevistados promove conversa informal e o entrevistado discorre de maneira aberta sobre o assunto (Boni e Quaresma, 2005). A entrevista foi realizada com os proprietários do quintal, sobre assuntos relacionados a questões sociais, econômicas e técnicas de manejo adotadas. Adicionalmente, as estruturas físicas da propriedade, bem como as características dos quintais florestais, foram capturas utilizando máquina fotográfica.

As áreas do sítio foram divididas em zoneamentos: Zona 0 (Casas); Zona 1 (Área próxima à moradia: criação de pequenos animais e horta); Zona 2 (Área afastada da zona 0: produção de sementes e fruteiras); Zona 3 (Área afastada da zona 0: Culturas anuais e pousio); Zona 4 (Área afastada da Zona 0: Plantio de Árvores, sistemas agroflorestais) e Zona 5 (Área mais afastada da Zona 0: Florestas nativas, áreas de piscicultura) (Figura 2). 


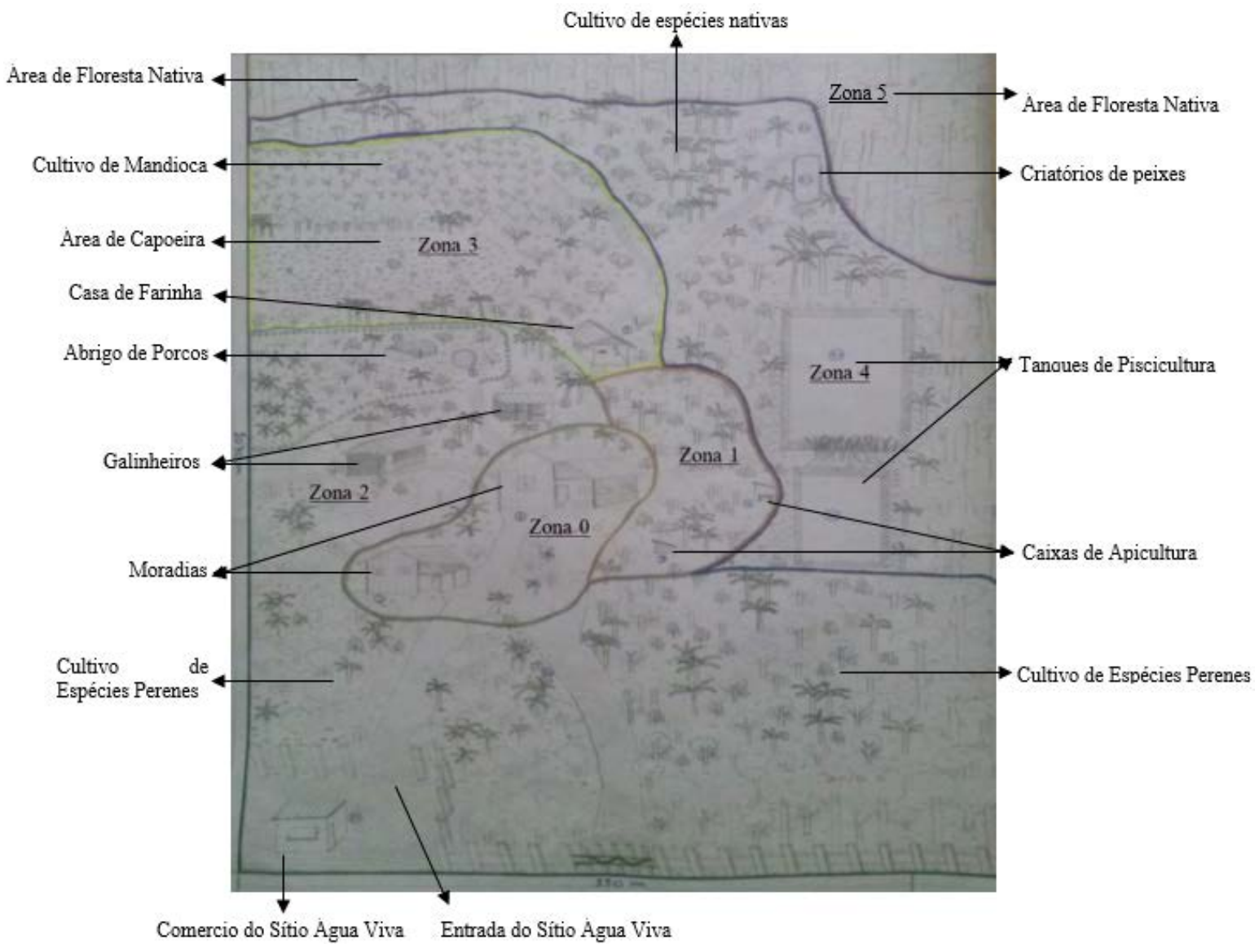

Figura 2. Discriminação das zonas agroflorestais e dos subsistemas do sítio Água Viva.

\section{Resultados e discussão}

\section{Caracterização física e socioeconômica}

Dentre as estruturas construídas na propriedade estão: Duas casa (Zona 0 ), sendo a principal da família e uma outra desocupada antigamente ocupada por outro familiar; um pequeno comércio na frente na propriedade (Zona 2); um galpão de utensílios, um galinheiro, um chiqueiro, um galpão de criação de patos e gansos e um cercado menos para criação de pintinhos (Zona 2); uma casa de farinha (Zona 3) e dois tanques de piscicultura (Zona 4).

Quanto aos cuidados empregados nesses subsistemas, o homem realiza as tarefas de cuidados dos cultivos, colheita de frutos e comercialização dos produtos, enquanto a mulher realiza afazeres domésticos e cuidados com os animais. De acordo com Pereira e Figueiredo Neto (2015), há uma diferenciação das atividades nos agroecossistemas, como os quintais agroflorestais, em que aproximadamente $50 \%$ são realizadas pelos homens e $50 \%$ pelas mulheres, raramente com contratação externa.

$\mathrm{Na}$ propriedade residiam quatro pessoas: Os proprietários (homem de 75 anos e mulher de 63 anos) que são aposentados, o filho mais novo do casal (26 anos) que é autônomo e a neta do casal (6 anos) estudante. Quase a totalidade da renda da propriedade vem dos benefícios provenientes da aposentadoria (dois salários mínimos mensais). As demais rendas advêm da venda de frutas e outros produtos vendidos no comércio gerando uma renda aproximada de um salário mínimo 
mensal em média. A venda de animais de criação, como galinhas, é variada e as estimativas são realizadas através do preço unitário de venda.
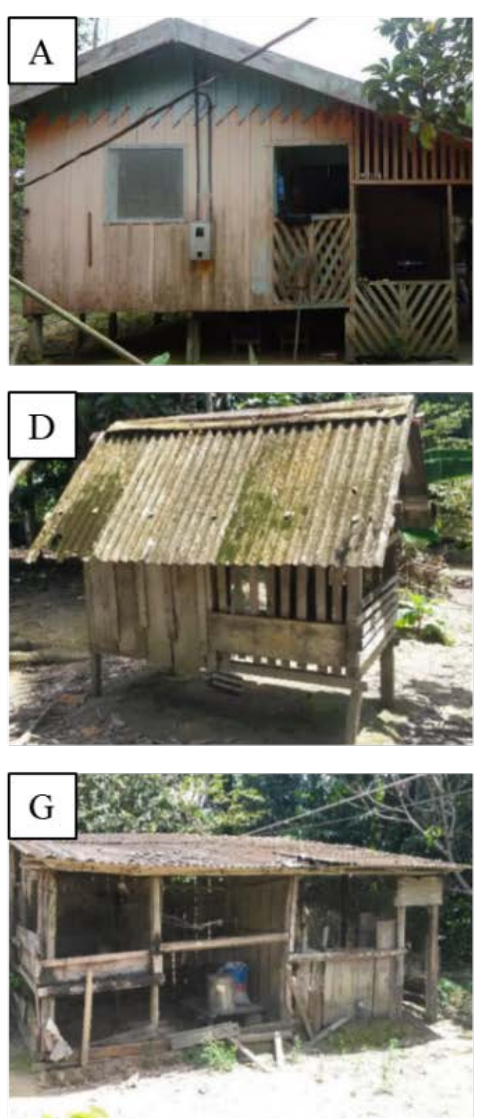
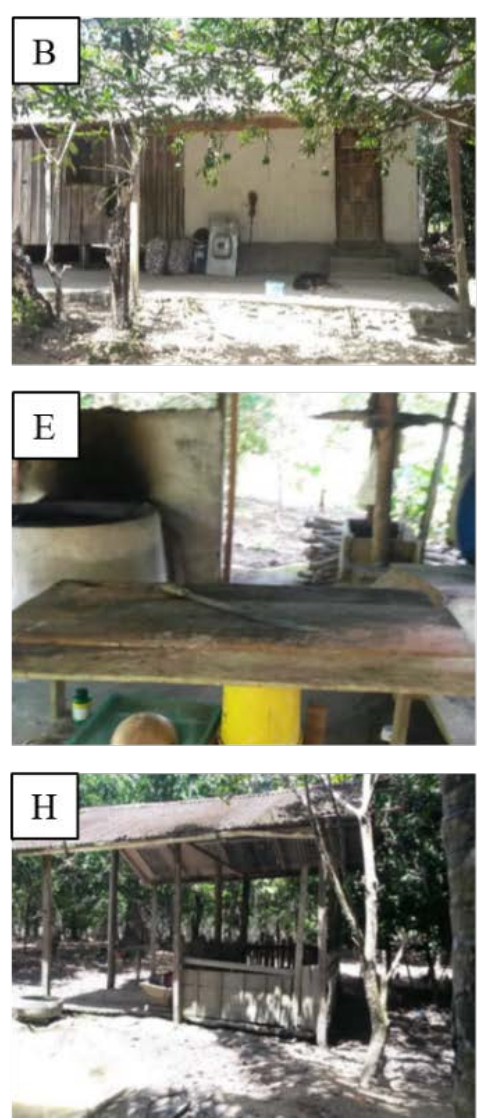
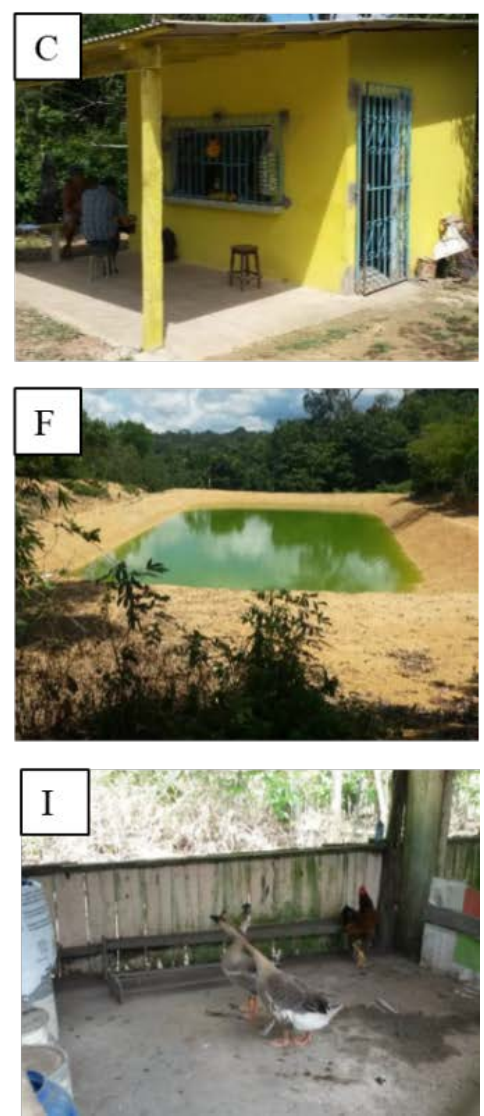

Figura 3. Construções dos subsistemas no quintal agroflorestal do sítio “Água Viva”. Casa Principal (A); Casa Secundária (B); Comércio (C); Abrigo de Pintinhos (D); Casa de Farinha (E); Tanque de Piscicultura (F); Galinheiro (G); Abrigo de Porcos (H); Abrigo de Gansos e Patos (I).

Em relação ao grau de escolaridade dos habitantes do quintal agroflorestal, os proprietário haviam concluído apenas o ensino fundamental, o filho do casal o ensino médio e a neta iniciando as atividades educacionais. No meio rural e em populações com idades mais avançadas é comum que se tenha baixa escolaridade presentes, sob justificativas de permuta da escolaridade regular pelas atividades laborais nos roçados com os pais (Amaral e Guarim Neto, 2008; Carniello et al., 2010). Segundo Costa et al. (2017), informações sobre escolaridade nesses ambientes são extremamente relevantes de forma a subsidiar ações governamentais de apoio, como financiamento e assistência técnica.

\section{Cultivos anuais e perenes}

No Sítio Água Viva eram produzidas e comercializadas várias espécies perenes, frutíferas e condimentares, a saber biribá, cupuaçu, laranja, maracujá, maracujá-do-mato, pupunha, rambutã, tucumã e pimentado-reino. No entanto os principais cultivos perenes plantados e comercializados são o biribá, cupuaçu, maracujá e rambutã. Foi relatado que em nenhum desses cultivos é realizado 
adubações, controle de pragas e doenças. 0 trato cultural mais comum de ser praticado é a atividade de poda, devido não demandar insumos externos.

Um dos principais problemas fitossanitários identificados na propriedade é a ocorrência da doença conhecida como vassoura-de-bruxa no cupuaçu, cujo agente etiológico é o fungo Moniliophthora perniciosa, cuja incidência é intensa no Amazonas (Gasparotto, 2000). Devido a não realização de controle químico ou cultural indicados para cultura, os cultivos estavam vastamente atacados, com sintomas característicos, como hipertrofia nas brotações e surgimento de gemas laterais ressecadas (Alves e Ferreira, 2012).
$\mathrm{Na}$ propriedade, o manejo da capoeira no roçado é realizado tradicionalmente, no modelo de cortequeima-pousio (Figura 4). A capoeira e o roçado estão localizados na Zona 3. Não são feitos nesses cultivos controle químico de pragas ou doenças, adubações químicas, porém é utilizado calcário no plantio de mandioca. De acordo com Pedroso Junior et al. (2008), em áreas da Amazônia Central, como no estado do Amazonas, é comum a agricultura de corte queima sendo que essas áreas tendem a se tornar improdutivas com cerca de dois anos após sua abertura, devido a não utilização de fertilizantes e corretivos.
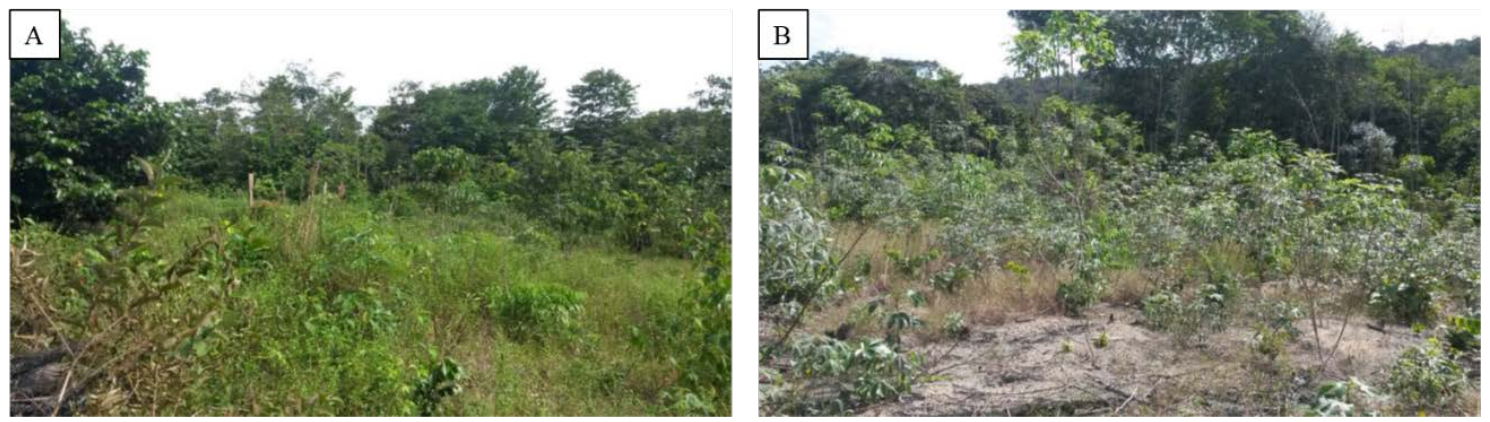

Figura 4. Área de pousio ou capoeira (A) e Cultivo de Mandioca (B).

\section{Criação de animais}

$\mathrm{Na}$ propriedade são criadas várias espécies avícolas, a saber galinhas, galinhas d'angola, gansos e patos. 0 destino dos animais de criação são a subsistência e comércio. As aves são alimentadas com restos de cozinha e de cultivos, milho e quirera para os pintinhos. Na propriedade eram criados três porcos que não são comercializados, servindo apenas para alimentação de subsistência em épocas festivas. A área de criação está na Zona 2.

$\mathrm{Na}$ ocasião do levantamento do quintal florestal, havia três caixas para produção de mel que estavam desativadas. Havia também dois tanques de piscicultura recentemente abertos (Zona 4). 0 primeiro aberto a três anos $(15 \mathrm{~m} \times 30 \mathrm{~m})$ e outro aberto a um ano (30 m x $50 \mathrm{~m}$ ). Assim como observado por Costa et al. (2017) em caracterização de quintais florestais na Amazônia, a maior parte dos animais criados em pequenas áreas e com manjo rudimentar destina-se a consumo próprio e de familiares próximos, sendo uma pequena parte destinada para venda, principalmente os derivados, como ovos e queijos. 

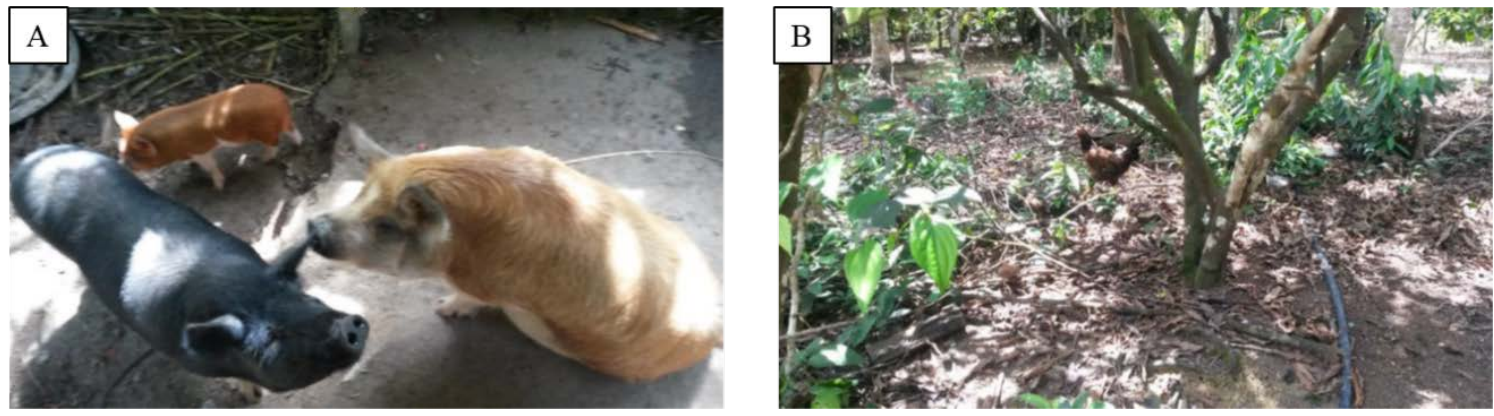

Figura 5. Porcos (A) e galinhas (B) criados no quintal agroflorestal.

\section{Biodiversidade vegetal}

No levantamento

da

biodiversidade vegetal, observou-se espécies nativas e espécies exóticas da Amazônia Brasileira (Tabela 1). De acordo com Nair (2006), a distribuição das espécies nos quintais são determinadas por alguns fatores internos e externos, tais como tamanho do quintal, preferência de alguns cultivos e fatores socioeconômicos. No quintal agroflorestal do sítio Água Viva foram encontradas 54 espécies, distribuídas em 35 famílias. Dentre todas as espécies vegetais, 36 são de origem exótica e 18 são nativas da Amazônia. Segundo Albuquerque et al. (2005), é comum observar a presença de algumas espécies nativas em quintais agroflorestais, no entanto, em todos há um predomínio de plantas exóticas.

As famílias mais representativas quanto a diversidade foram Arecaceae (6 spp.), Myrtaceae (5 spp.), e Poaceae (3 spp.). Dentre as espécies verificadas, as identificadas como mais comuns aos quintais agroflorestais tropicais, segundo Albuquerque et al. (2005), Musa paradisiaca, Cocos nucifera, Psidium guajava, Mangifera indica, Carica papaya e Citrus sp., foram encontradas nestes quintais. Segundo Garcia et al. (2015), a maior diversidade de espécies proporciona maior eficiência no fornecimento de produtos ao longo do ano, devido a sazonalidade de produção, assegurando a subsistência dos produtores.

Tabela 1. Espécies presentes no quintal agroflorestal do sítio “Água Viva”, no município de Manaus, Amazonas (Brasil).

\begin{tabular}{|c|c|c|c|c|}
\hline Família & Espécie & Origem & Nome comum & Uso \\
\hline \multirow[t]{6}{*}{ Arecaceae } & Euterpe oleracea & Nativa & Açai & Alimentar \\
\hline & Oenocarpus bacaba & Nativa & Bacaba & Alimentar \\
\hline & Mauritia flexuosa & Nativa & Buriti & Alimentar \\
\hline & Cocus nucifera & Exótica & Coco & Alimentar \\
\hline & Bactris gasipaes & Nativa & Pupunha & Alimentar \\
\hline & Astrocaryum aculeatum & Nativa & Tucumã & Alimentar \\
\hline Alliaceae & Allium fistulosum & Exótica & Cebolinha & Condimentar \\
\hline \multirow[t]{2}{*}{ Anacardiaceae } & Anacardium occidentale & Exótica & Caju & Alimentar \\
\hline & Mangifera indica & Exótica & Manga & Alimentar \\
\hline Anonaceae & Rollineamucosa & Exótica & Biribá & Alimentar \\
\hline Apiaceae & Coriandrum sativum & Exótica & Coentro & Condimentar \\
\hline
\end{tabular}


Tabela 1. Continuação.

\begin{tabular}{|c|c|c|c|c|}
\hline Família & Espécie & Origem & Nome comum & Uso \\
\hline Asparagaceae & Sansevieria trifasciata & Exótica & $\begin{array}{l}\text { Espada-de-são- } \\
\text { jorge }\end{array}$ & Medicinal \\
\hline \multirow[t]{2}{*}{ Bignonaceae } & Crescentia cuiete & Exótica & Cabaça & $\begin{array}{c}\text { Não- } \\
\text { madeireiro }\end{array}$ \\
\hline & Arrabidaea chica & Nativa & Crajiru & Medicinal \\
\hline Bixaceae & Bixa orellana & Nativa & Urucum & Condimentar \\
\hline Bromeliaceae & Ananas comosus & Exótica & Abacaxi & Alimentar \\
\hline Caricaceae & Carica papaya & Exótica & Mamão & Alimentar \\
\hline Chrysobalanaceae & Couepia bracteosa & Nativa & Pajurá & Medicinal \\
\hline Euphorbiaceae & $\begin{array}{c}\text { Manihot esculenta } \\
\text { Copaifera langsdorfii }\end{array}$ & $\begin{array}{l}\text { Nativa } \\
\text { Nativa }\end{array}$ & $\begin{array}{l}\text { Mandioca } \\
\text { Copaíba }\end{array}$ & $\begin{array}{l}\text { Alimentar } \\
\text { Não- } \\
\text { madeireiro }\end{array}$ \\
\hline Fabaceae & $\begin{array}{c}\text { Ingamacrophylla } \\
\text { Inga fagifolia }\end{array}$ & $\begin{array}{l}\text { Exótica } \\
\text { Exótica }\end{array}$ & $\begin{array}{c}\text { Ingá } \\
\text { Ingá-de-macaco }\end{array}$ & $\begin{array}{l}\text { Alimentar } \\
\text { Alimentar }\end{array}$ \\
\hline Icacinaceae & Poraqueiba sericea & Nativa & Mari & Alimentar \\
\hline Lamiaceae & $\begin{array}{c}\text { Mentha spicata } \\
\text { Ocimum basilicum }\end{array}$ & $\begin{array}{l}\text { Exótica } \\
\text { Exótica }\end{array}$ & $\begin{array}{c}\text { Hortelã } \\
\text { Manjericão }\end{array}$ & $\begin{array}{l}\text { Condimentar } \\
\text { Condimentar }\end{array}$ \\
\hline Lauraceae & $\begin{array}{l}\text { Persea americaca } \\
\text { Aniba roseadora }\end{array}$ & $\begin{array}{l}\text { Exótica } \\
\text { Nativa }\end{array}$ & $\begin{array}{l}\text { Abacate } \\
\text { Pau-rosa }\end{array}$ & $\begin{array}{c}\text { Alimentar } \\
\text { Sombreamento }\end{array}$ \\
\hline Lecythidaceae & Bertholletia excelsa & Nativa & Castanheira & Sombreamento \\
\hline Liliaceae & Aloe vera & Exótica & Babosa & Medicinal \\
\hline Malvaceae & Theobroma grandiflorum & Nativa & Cupuaçu & Alimentar \\
\hline Meliaceae & Carapa guianensis & Nativa & Andiroba & Sombreamento \\
\hline Moraceae & Artocarpus heterophyllus & Exótica & Jaca & Alimentar \\
\hline Musaceae & Musa paradisiaca & Exótica & Banana & Alimenta \\
\hline Myrtaceae & $\begin{array}{c}\text { Psidium guajava } \\
\text { Eugenia estipitata } \\
\text { Syzygium cumini } \\
\text { Plinia cauliflora } \\
\text { Sizygium malaccense }\end{array}$ & $\begin{array}{l}\text { Exótica } \\
\text { Nativa } \\
\text { Exótica } \\
\text { Exótica } \\
\text { Exótica } \\
\end{array}$ & $\begin{array}{c}\text { Goiaba } \\
\text { Araça-boi } \\
\text { Azeitona-preta } \\
\text { Jabuticaba } \\
\text { Jambo }\end{array}$ & $\begin{array}{l}\text { Alimentar } \\
\text { Alimentar } \\
\text { Alimenta } \\
\text { Alimentar } \\
\text { Alimentar } \\
\end{array}$ \\
\hline Oxalidaceae & Averrhoa carambola & Exótica & Carambola & Alimentar \\
\hline Passifloraceae & $\begin{array}{c}\text { Passiflora edulis } \\
\text { Passiflora cincinnata }\end{array}$ & $\begin{array}{l}\text { Exótica } \\
\text { Exótica }\end{array}$ & $\begin{array}{c}\text { Maracujá } \\
\text { Maracujá-do- } \\
\text { mato } \\
\end{array}$ & $\begin{array}{l}\text { Alimentar } \\
\text { Alimentar }\end{array}$ \\
\hline Piperaceae & Piper nigrum & Exótica & $\begin{array}{l}\text { Pimenta-do- } \\
\text { reino }\end{array}$ & Condimentar \\
\hline Poaceae & $\begin{array}{c}\text { Cymbopogon citratus } \\
\text { Bambusa vulgaris } \\
\text { Saccharum. officinarum }\end{array}$ & $\begin{array}{l}\text { Exótica } \\
\text { Exótica } \\
\text { Exótica }\end{array}$ & $\begin{array}{c}\text { Capim-santo } \\
\text { Bambu } \\
\text { Cana-de-açúcar }\end{array}$ & $\begin{array}{l}\text { Medicinal } \\
\text { Ornamental } \\
\text { Alimentar }\end{array}$ \\
\hline Rubiaceae & $\begin{array}{l}\text { Coffea canefhora } \\
\text { Morinda citrifolia }\end{array}$ & Exótica & Café & $\begin{array}{l}\text { Não- } \\
\text { madeireiro } \\
\text { Medicinal }\end{array}$ \\
\hline Rutaceae & $\begin{array}{c}\text { Citrus sinenses } \\
\text { Citrus limon }\end{array}$ & $\begin{array}{l}\text { Exótica } \\
\text { Exótica }\end{array}$ & $\begin{array}{l}\text { Laranja } \\
\text { Limão }\end{array}$ & $\begin{array}{l}\text { Alimentar } \\
\text { Alimentar }\end{array}$ \\
\hline Sapindaceae & Nephelium lappaceum & Exótica & Rambutã & Alimentar \\
\hline Sapotaceae & Pouteria macrophylla & Nativa & Abiu & Alimentar \\
\hline Solanaceae & $\begin{array}{l}\text { Solanum sessiliflorum } \\
\text { Solanum lycopersicum }\end{array}$ & $\begin{array}{l}\text { Nativa } \\
\text { Exótica }\end{array}$ & $\begin{array}{l}\text { Cubiu } \\
\text { Tomate }\end{array}$ & $\begin{array}{l}\text { Alimentar } \\
\text { Alimentar }\end{array}$ \\
\hline Urticaceae & Cecropiapachystachya & Exótica & Embaúba & Sombreamento \\
\hline
\end{tabular}


Dentre as espécies mais encontradas em maior densidade no quintal agroflorestal, estão o cupuaçu (Theobroma grandiflorum), açaí (Euterpe oleracea), mandioca (Manihot esculenta), mari (Poraqueiba sericea) e pimenta-doreino (Piper nigrum), todas nativa da Região Amazônica, a exceção da pimentado-reino. De acordo com Veiga e Scudeller (2011), a grande diversidade de espécies em quintais agroflorestais na Amazônia estão ligadas a diversificação de espécies para subsistência familiar, sejam alimentares ou medicinais.

Dentre as 54 espécies vegetais presentes, 34 deles tem uso alimentar como função prioritária, o que significa cerca de $63 \%$ das espécies para este fim. Nos estudos de Costa et al. (2017) observou-se que $57,3 \%$ das espécies estavam destinadas a alimentação em um quintal agroflorestal Amazônico. Segundo Saviero et al. (2011), entre as espécies alimentares, as frutíferas são as principais responsáveis por garantir a qualidade da alimentação do residentes.

Dentre os cultivos anuais, a mandioca (Manihot esculenta) foi a principal cultivada na área, devido principalmente a fabricação de farinha típica da região e posteriormente venda na qualidade. Além de ser a principal cultura anual do Amazonas, o cultivo de mandioca, mesmo desconsiderando os aspectos técnicos de cultivo, assume importância relevante na alimentação local e tradicional, sendo também amplamente utilizada para fabricação de outros produtos industriais (Pedro et al., 2013).

Embora menos frequentes que as espécies alimentares, as espécies arbóreas estavam presentes no quintal agroflorestal, principalmente a castanheira-do-Brasil (Bertholletia excelsa), andiroba (Carapa guianensis) e pau-rosa (Aniba roseadora). Em geral as espécies as espécies arbóreas dominam os quintais agroflorestais na Amazônia (Sablayrolles e Andrade, 2009). Para Figueiredo et al. (2013), a importância dos quintais florestais vai além da base alimentar, mas também pelo sombreamento proporcionado pelas árvores, trazendo lazer a família e a comunidade.

As espécies medicinais e condimentares também foram encontradas no quintal agroflorestal estudado e possuem os mais diversos usos. De acordo com Wezel e Bender (2003), essas espécies são normalmente cultivadas em áreas mais restritas por demandarem maiores cuidados e geralmente próximas a locais de preparo de alimentos, sendo comum em quintais agroflorestais tropicais.

\section{Conclusão}

Os residentes do quintal agroflorestal apresentam baixa e escolaridade e não possuem posse definitiva da terra. Os cultivos são manejados com baixa tecnologia, sem insumos externos, que favorece a conservação do meio ambiente.

Dentre os cultivos perenes, o mais abundante é o cupuaçu (Theobroma grandiflorum) e entre os cultivos anuais o mais abundante é a mandioca (Manihot esculenta).

Mais de $60 \%$ das espécies vegetais do quintal agroflorestal estudado são destinadas à alimentação de subsistência e à geração de renda.

\section{Conflitos de interesse}

Os autores declaram não haver conflitos de interesse.

\section{Referências}

Aguiar, J.; Fraxe, T. J. P.; Castro, A. P.; Silva, A. C. P. Reprodução socioeconômica e cultural através do manejo de sistemas agroflorestais por caboclos-ribeirinhos em comunidades do Amazonas. Revista Brasileira de Agroecologia, v. 4, n. 2, p. 4195-4198, 2009.

Albuquerque, U.P.; Cavalcanti, L. H.; Caballero, J. Structure and floristics of homegardens in Northeastern Brazil. Journal of Arid Enviroments, v. 62, n. 3, p. 491-506, 
2005.

https://doi.org/10.1016/j.jaridenv.2005.01.0 03

Almeida, L. S.; Gama, J. R. V. Quintais agroflorestais: estrutura, composição florística e aspectos socioambientais em área de assentamento rural na Amazônia brasileira. Revista Ciência Florestal, v. 24, n. 4, p. 1041-1053, 2014. https://doi.org/ 10.1590/1980-509820142404023

Alves, R. M.; Frreira, F. N. BRS Carimbó: a nova cultivar de cupuaçuzeiro da Embrapa Amazônia Oriental. Belém: Embrapa Amazônia Oriental, 2012. (Comunicado técnico).

Amaral, C. N.; Guarim Neto, G. Os quintais como espaços de conservação e cultivo de alimentos: um estudo na Cidade de Rosário Oeste. Boletim do Museu Paraense Emílio Goeldi, $\quad$ v. $3, \quad$ n. 3 p. 329-341, 2008. https://doi.org/10.1590/S1981-81222008 000300004

Boni, V.; Quaresma, S. J. Aprendendo a entrevistar: como fazer entrevistas em Ciências Sociais. Revista Eletrônica dos Pós-Graduandos em Sociologia Política da UFSC, v. 2, n.1, p. 68-80, 2005.

Carneiro, M. G. R.; Camurça, A. M.; Esmeraldo, G. G. S. L.; Sousa, N. R. Quintais produtivos: contribuição à segurança alimentar e ao desenvolvimento sustentável local na perspectiva da agricultura familiar (o caso do Assentamento Alegre, Município de Quixeramobim/CE). Revista Brasileira de Agroecologia, v. 8, n. 2, p. 135-147, 2013.

Castro, A. P.; Fraxe, T. J. P.; Santiago, J. L.; Matos, R. B.; Pinto, I. C. Os sistemas agroflorestais como alternativa de sustentabilidade em ecossistemas de várzea no Amazonas. Acta Amazônica, v. 39, n. 2, p. 279-288, 2009. https://doi.org/10.1590/ S0044-59672009000200006

Costa, G. C.; Moura, N. D. S.; Farias, A. K. D.; Alho, E. A.; Jucoski, G. O. Caracterização socioeconômica e levantamento de espécies vegetais em quintais agroflorestais da zona rural do Município de Parauapebas, Pará. Agroecossistemas, v. 9, n. 1, p. 199-211, 2017. https://doi.org/10.18542/ragros. v9i1.4653

Costa, J. R; Mitja, D. Uso dos recursos vegetais por agricultores familiares de Manacapuru (AM). Acta Amazonica, v. 40, n. 1, p. 49-58,
$2010 . \quad$ https://doi.org/10.1590/S004459672010000100007

Figueiredo Júnior, O.; Hamada, M. O. S.; Souza, S. P. O.; Correa, R. F. Levantamento florístico dos quintais agroflorestais do PDS Virola Jatobá em Anapu, Pará. Enciclopédia Biosfera, v. 9, n. 17, p. 1793-1805, 2013.

Garcia, R.; Vieira, T. A.; Oliveira, F. A. Quintais agroflorestais e segurança alimentar em uma comunidade rural na Amazônia Oriental. Revista de la Facultad de Agronomía, v. 114, n. 3, p. 67-73, 2015.

Gasparotto, L.; Pereira, J. C. R. Epidemiologia da vassoura-de-bruxa (Crinipellis perniciosa) do cupuaçuzeiro (Theobroma grandiflorum). Manaus: Embrapa Amazônia Ocidental, 2000. (Embrapa Amazônia Ocidental; Boletim de Pesquisa).

Gazel Filho, A. B. Composição, estrutura e função de quintais agroflorestais no Município de Mazagão, Belém. Belém: Universidade Federal Rural da Amazônia, 2008. (Tese de doutorado).

Gomes, GS. Quintais agroflorestais no Município de Irati-Paraná, Brasil: agrobiodiversidade e sustentabilidade socioeconômica e ambiental. Curitiba: Universidade Federal do Paraná, 2010. (Tese de doutorado).

Köppen, W. Climatologia: con un studio de los climas de la tierra. México: Fondo de Cultura Economica, 1948.

Nair, P. K. R. The role of soil science in the sustainability of agroforestry systems: eliminating hunger and poverty. In: GamaRodrigues, A. C.; Gama-Rodrigues, A. C.; Barros, N. F.; Gama-Rodrigues, E. F.; Freitas, M. S. M.; Viana, A. P.; Jasmin, J. M.; Marciano, C. R.; Carneiro, J. G. A. (Eds.). Sistemas agroflorestais: bases para 0 desenvolvimento sustentável. Campos dos Goytacazes: Universidade Estadual do Norte Fluminense Darcy Ribeiro, 2006. p. 203-216.

Pedro, L. P. M.; Cunha, A. P. Cardoso, E. L. M. Cultivo da mandioca para o Estado do Pará. 2013. Disponível em: <http://sistemas deproducao.cnptia.embrapa.br/FontesHTML /Mandioca/mandioca_para/>. Acesso em: 23 jan. 2019.

Pedroso Junior, N. N.; Murrieta, R. S. S.; Adams, C. A agricultura de corte e queima: um sistema em transformação. Boletim do 
Museu Paraense Emílio Goeldi, v. 3, n. 2, 153-174, 2008. https://doi.org/10.1590/ S1981-81222008000200003

Pereira, P. V. M.; Figueiredo Neto, L. F. Conservação de espécies florestais: um estudo em quintais agroflorestais no Município de Cáceres-MT. Revista Eletrônica em Gestão, Educação e Tecnologia Ambiental, v. 19, n. 1, p. 783-793, 2015.

Rodrigues, T. E. Solos da Amazônia. In: Alvarez, V. H.; Fontes, L. E. F.; Fontes, M. P. F. 0 solo nos grandes domínios morfoclimáticos do Brasil e o desenvolvimento sustentado. Viçosa: Sociedade Brasileira de Ciência do Solo, 1996. p. $19-60$.

Sablayrolles, M. G. P.; Andrade, L. Entre sabores e saberes: a importância dos quintais agroflorestais para agricultores ribeirinhos no Tapajós-PA. Anais do Congresso Brasileiro de Sistemas Agroflorestais, Brasília, 2009.
Saviero, A.; Delunardo, T. A.; Haverroth, M.; Oliveira, L. C.; Mendonça, A. M. S. Cultivo de espécies alimentares em quintais urbanos de Rio Branco, Acre, Brasil. Acta Botânica Brasílica, v. 25, n. 3, p. 549-556, 2011. https://doi.org/10.1590/S0102-330620110 00300006

Veiga, J. B.; Scudeller, V. V. Quintais agroflorestais da comunidade ribeirinha São João do Tupé no Baixo Rio Negro, Amazonas. In: Santos-Silva, E. N.; Cavalcante, M. J.; Scudeller, V. V. (Orgs.). BioTupé: meio físico, diversidade biológica e sociocultural do Baixo Rio Negro, Amazônia Central. Manaus: INPA, 2011. p. 523-543.

Wezel, A.; Bender, S. Plant species diversity of homegardens of Cuba and its significance for household food supply. Agroforestry Systems, v. $57, \quad$ n. $1, \quad$ p. 39-49, 2003. https://doi.org/10.1023/A:1022973912195

Informação da Licença: Este é um artigo Open Access distribuído sob os termos da Licença Creative Commons Attribution, que permite uso irrestrito, distribuição e reprodução em qualquer meio, desde que a obra original seja devidamente citada. 